Published as: Oliver, J.J. (2020). Corporate turnaround failure: is the proper diagnosis transgenerational response? Strategy \& Leadership, Vol.48, Issue 3, pp.37-43

\title{
Corporate turnaround failure: is the proper diagnosis transgenerational response?
}

Could there be a hidden cause of chronic failure in a corporation, where over many years multiple CEOs and new strategies can't revitalize the firm after a past painful stumble? An emerging theory is that the persistent after effects of a cultural, managerial or economic trauma can cripple an organization's serial turnaround attempts. But the conventional approach by business executives and management consultants is to treat every problematic corporate rehabilitation as a routine "turnaround case." In fact, some organizations exhibiting chronic underperformance may actually be suffering from the residual effects of a crisis event that occurred a number of years previously. To identify such hidden trauma, corporate leaders should consider applying a thought-provoking concept from the field of Epigenetics to better understand chronic turnaround cases.

Public health medicine recognizes a syndrome called "Transgenerational Response," which describes how a severe environmental trauma can create an inherited adaptive response in the epigenome of an organism that influences the development and health of future generations.

In human biology, an epigenome is defined as a network of chemical compounds surrounding DNA that modify the genome without altering the DNA sequences and have a role in determining which genes are active in a particular cell.

Research studies into epigenetics as a medical phenomenon include:

- Examining the transgenerational effects of maternal malnutrition influencing the development and health of future generations.[1]

- The consequence of traumatic experiences, such as war and the holocaust, where the off-spring of survivors have inherited negative psychological and behavioral characteristics.[2]

- Examination into the effects of post-traumatic stress disorder (PTSD) in babies of mothers exposed to the World Trade Center attack in 2001 during their pregnancy.[3] The study concluded that the effects of maternal PTSD, as a result of this catastrophic event, were passed on to their babies as evidenced by a significantly smaller than average birth weight and a permanent vulnerability to depression, stress related illnesses and an increased distress response to current events.

So can a corporate crisis event create dysfunctional adaptive attitudes and behaviors that subsequently become embedded in the culture of a firm to the detriment of its long-term viability and performance? With many researchers analyzing corporate culture in terms of "corporate DNA" it's not farfetched to believe that the notion of transgenerational response in relation to company crisis events deserves serious attention.

\section{Corporate DNA: it's culture that drives performance!}

Corporate culture is widely regarded as the collective cognition of implied assumptions and shared beliefs that differentiate one organization from another. It also creates a tacit social order that shapes and regulates attitudes, behaviors and social norms toward a shared organizational goal that aims to enhance performance through the aspirational commitment of employees. Observers have also noticed that organizations can be "held captive" by their culture when its values and beliefs act as an invisible barrier against change. Why a culture 
Published as: Oliver, J.J. (2020). Corporate turnaround failure: is the proper diagnosis transgenerational response? Strategy \& Leadership, Vol.48, Issue 3, pp.37-43

unconsciously perpetuates a less than optimal status quo is relevant when considering why an organization stymies efforts to promote adaptation and change. Could the cause be the impact of a past crisis event on organizational culture? And if so, does such a crisis result in a dysfunctional evolutionary cultural adaptation in the firm, or does it limit the organization to adopting a no-change scenario because of a learned response to trauma?

Corporate culture also drives long-term performance, with firms being either open, or resistant, to the idea of innovation and of developing a strategic outlook, investments, systems, people and processes that deliver products, services and improved business performance valued by customers.[4] Equally, well-planned and well-led risk taking is closely linked to superior corporate performance.

\section{The cases of AIG and Yahoo}

It's time, now that several more years have passed since a previous analysis, for an update on the long-term effect of historic crisis events that crippled AIG and Yahoo, two firms that were examined for "transgenerational response" trauma in 2017. Instead of just looking at the short-term view of how a crisis situation was managed, there can now be a longer-term consideration of the transgenerational effects and adaptive responses in the firms' corporate culture. This approach specifically emphasizes the attitudes and behaviors supporting innovation and risk and the subsequent corporate financial underperformance of firms suffering from post-trauma effects.

\section{Transgenerational response: further evidence from two cases}

\section{AIG: critical corporate incident}

AIG is a global insurance firm that provides a range of insurance and financial services to individual and business customers in 80 countries. On February 2, 2005, it was charged with accounting fraud and bid rigging by the U.S. Securities and Exchange Commission, the U.S. Justice Department and the New York State Attorney General's Office. The fraud, estimated at $\$ 3.9$ billion, involved loans that were booked as revenue, a practice intended to inflate AIG's share price. Among the first consequences of this deception was a \$1.64 billion fine levied by the U.S. Securities and Exchange Commission and the firing of long-term AIG CEO Maurice Greenberg. Since the date of this Critical Corporate Incident (CCI), AIG's share price has fallen by 96 percent, as compared to rises in the S\&P $500(+155$ percent) and a major competitor, the Progressive Corp (+249 percent).

\section{AIG: corporate generations}

Since 2005, seven CEOs have been unable to manage a turnaround in the company's fortunes. The average CEO tenure since the CCI is two years, far short of the average job length of 9.9 years for an S\&P 500 CEO.[5]

\section{AIG: corporate financial performance}

The Global Financial Crisis of 2008 resulted in the U.S. federal government bailing out AIG to the tune of $\$ 182$ billion in a bid to stave off a global economic recession that would result in the bankruptcy of numerous financial institutions that held AIG debt. While this financial crisis has influenced AIG's corporate financial performance, research indicates that things started to go wrong from the date that it was charged with accounting fraud in 2005. Exhibit 1 shows that the average values of Market Capitalization, Operating Income and EBIT before the CCI are in stark contrast to the pre- and post-incident figures. 
Published as: Oliver, J.J. (2020). Corporate turnaround failure: is the proper diagnosis transgenerational response? Strategy \& Leadership, Vol.48, Issue 3, pp.37-43

Exhibit 1: AIG Financial Performance

\begin{tabular}{|c|c|c|c|c|}
\hline AIG & $\begin{array}{c}\text { Pre- } \\
\text { Incident } \\
5 y r \\
\text { Average } \\
(2000-04)\end{array}$ & $\begin{array}{c}\text { Critical } \\
\text { Corporate } \\
\text { Incident } \\
(2005)\end{array}$ & $\begin{array}{c}\text { Post-Incident } \\
13 y r \\
\text { Average } \\
(2006-18)\end{array}$ & $\begin{array}{c}\text { Change in } \\
\text { Pre \& Post } \\
\text { CCI } \\
\text { Averages } \\
(\%)\end{array}$ \\
\hline Market Value (US\$ Mn) & 176032 & 142953 & 73685 & -58 \\
\hline Operating Income (US\$ 000) & 14585400 & 21336000 & 7647615 & -48 \\
\hline EBIT (US\$ 000) & 15171000 & 20947000 & 2385077 & -84 \\
\hline
\end{tabular}

Source: Adapted from Thomson Reuters Datastream

\section{AIG: adaptive cultural change}

The data on cultural change issues at AIG, based on an analysis of language in public company communications, offers compelling evidence of the effects of trauma. Between 2005-17 the number of innovation words increased by 59 percent. Over the same period, however, the number of risk words increased by 654 percent. Moreover, the gap between these word frequencies has significantly diverged since the CCI (see Exhibit 2). This evidence is in contrast to the company's announcement in 2006 that its "culture was inherently strong and resilient"[6] and that its growth strategy sought to develop innovative new products that would see the company entering emerging new markets across the globe. Instead, the Global Financial Crisis resulted in a near collapse of the firm, and between 200811, corporate "governance and accountable management" became a primary area of strategic focus. The years between 2012-17 saw a firm that had become both "smaller and more focused," "simplified" and in the "midst of transformation" with less of an emphasis on innovation, but an increased awareness of risk.

Exhibit 2: AIG innovation and risk word use frequency

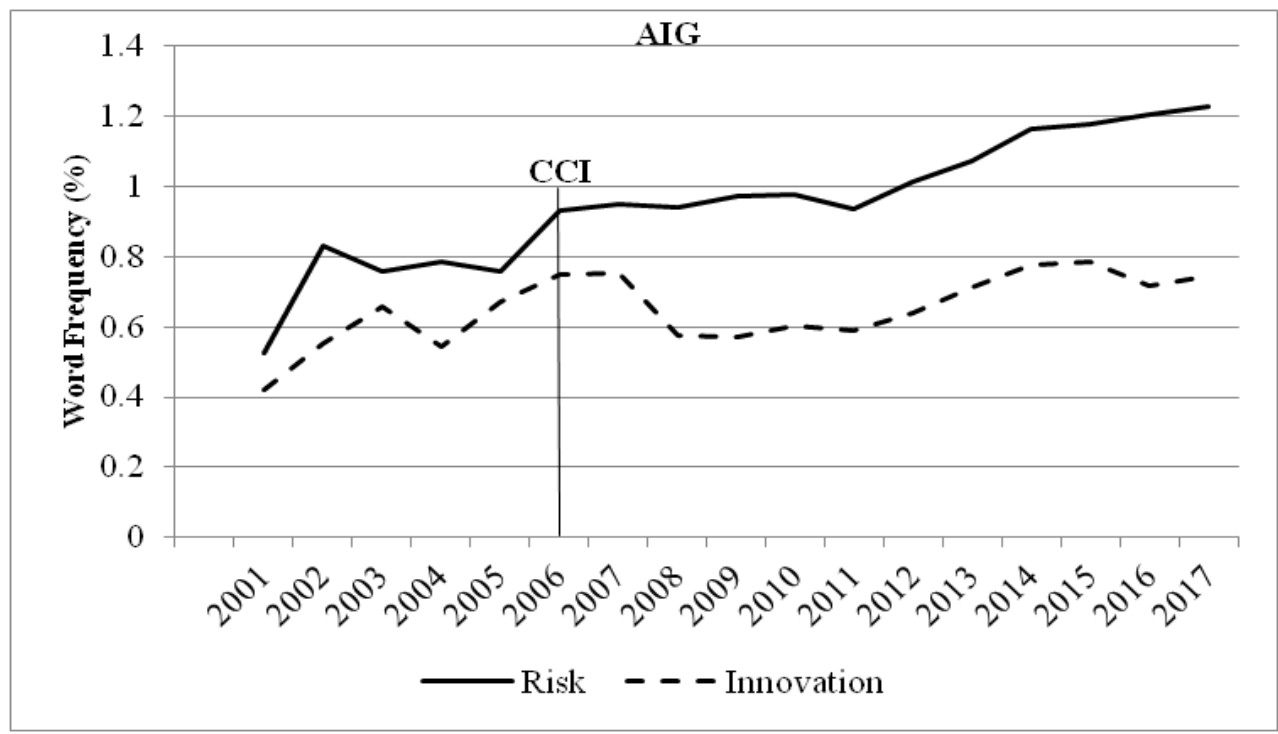


Published as: Oliver, J.J. (2020). Corporate turnaround failure: is the proper diagnosis transgenerational response? Strategy \& Leadership, Vol.48, Issue 3, pp.37-43

\section{Yahoo: critical corporate incident}

Yahoo, a pioneer of internet search and online services in the 1990s, was once ranked as one of the top websites in the U.S., but its stock fell precipitously after the dot.com bubble burst in 2001. On February 1, 2008, Microsoft Corporation made a hostile bid to acquire Yahoo for US $\$ 44.6$ billion in an attempt to combat the growing power and dominance of Google. The proposed acquisition made sense on a number of levels for both parties, but ultimately it collapsed due to the differences of opinion in the valuation of Yahoo. The failure of the deal was a Critical Corporate Incident for Yahoo, which was in an increasingly precarious position in its markets. The firm struggled with increased competition and its performance has been poor since the CCI. Yahoo ceased to be an independent operating company in 2017.

Yahoo: corporate generations

Arguably, the fallout from this hostile bid has affected subsequent generations of Yahoo managers who saw six CEOs take the helm. The average CEO tenure for Yahoo since the CCI was just 1.83 years. While Yahoo was hiring and firing CEOs, changing strategy, restructuring operations and cost-cutting, Google was innovating, dominating market share and expanding the strategic scope of its activities with impressive results.

\section{Yahoo: corporate financial performance}

Yahoo's financial performance has been variable since the 2008 event, with declines in the average market value, operating income and EBIT figures, pre- and post-CCI. In 2008, much of the discussion in the annual report centered on "innovation" and "product development," however, in the ensuing years, the discussion changed to how Yahoo could deliver value. Initially, it aimed at advertisers and consumers with a strategy that focused on mobile, video, native and social advertising. But then the value proposition turned to a consideration of shareholder returns in 2014 with a Strategic Review Committee exploring the potential sale of Yahoo's operating business. The transformation of the "company to greatness" was halted and 120 non-strategic legacy products and features were closed. Yahoo sold its 15 percent stake in Alibaba, the Chinese e-commerce company for $\$ 9.4$ billion. Shareholders were informed that "with more than two decades of rich history, this is Yahoo's moment to realize the tremendous value in our business."[7] Yahoo was sold to Verizon Communications for \$4.83 billion in 2017 (Exhibit 3).

Exhibit 3: Yahoo Financial Performance

\begin{tabular}{|c|c|c|c|c|}
\hline Yahoo & $\begin{array}{c}\text { Pre-Incident } \\
\text { 8yr Average } \\
(2000-07)\end{array}$ & $\begin{array}{c}\text { Critical } \\
\text { Corporate } \\
\text { Incident } \\
(2008)\end{array}$ & $\begin{array}{c}\text { Post-Incident } \\
\text { 8yr Average } \\
(2009-16)\end{array}$ & $\begin{array}{c}\text { Change in } \\
\text { Pre \& Post } \\
\text { CCI } \\
\text { Averages } \\
(\%)\end{array}$ \\
\hline Market Value (US\$ 000) & 36092160 & 35978100 & 27696086 & -23 \\
\hline $\begin{array}{c}\text { Operating Income (US\$ } \\
000)\end{array}$ & 505137 & 607354 & 375699 & -26 \\
\hline EBIT (US\$ 000) & 533282 & 95801 & 1031198 & $-127^{1}$ \\
\hline
\end{tabular}

Source: Adapted from Thomson Reuters Datastream

\footnotetext{
${ }^{1}$ EBIT figure has been adjusted so as not to take into account the $\$ 9.4 \mathrm{bn}$ windfall sale of the $15 \%$ stake in Alibaba
} 
Published as: Oliver, J.J. (2020). Corporate turnaround failure: is the proper diagnosis transgenerational response? Strategy \& Leadership, Vol.48, Issue 3, pp.37-43

\section{Yahoo: adaptive cultural change}

A word frequency analysis of Yahoo corporate communications found that risk words rose by 42 percent since the CCI in 2008, while the number of innovation words rose by just 23 percent over the same period. The result is that since the CCI, the gap between innovation and risk related word frequencies has narrowed (see Exhibit 4) almost to the point where the company appear to have been resistant to innovation. This lack of experimentation and the unwillingness to anticipate market opportunities has more than likely contributed to Yahoo's poor financial performance over the long-term.

Exhibit 4: Yahoo innovation and risk word use frequency

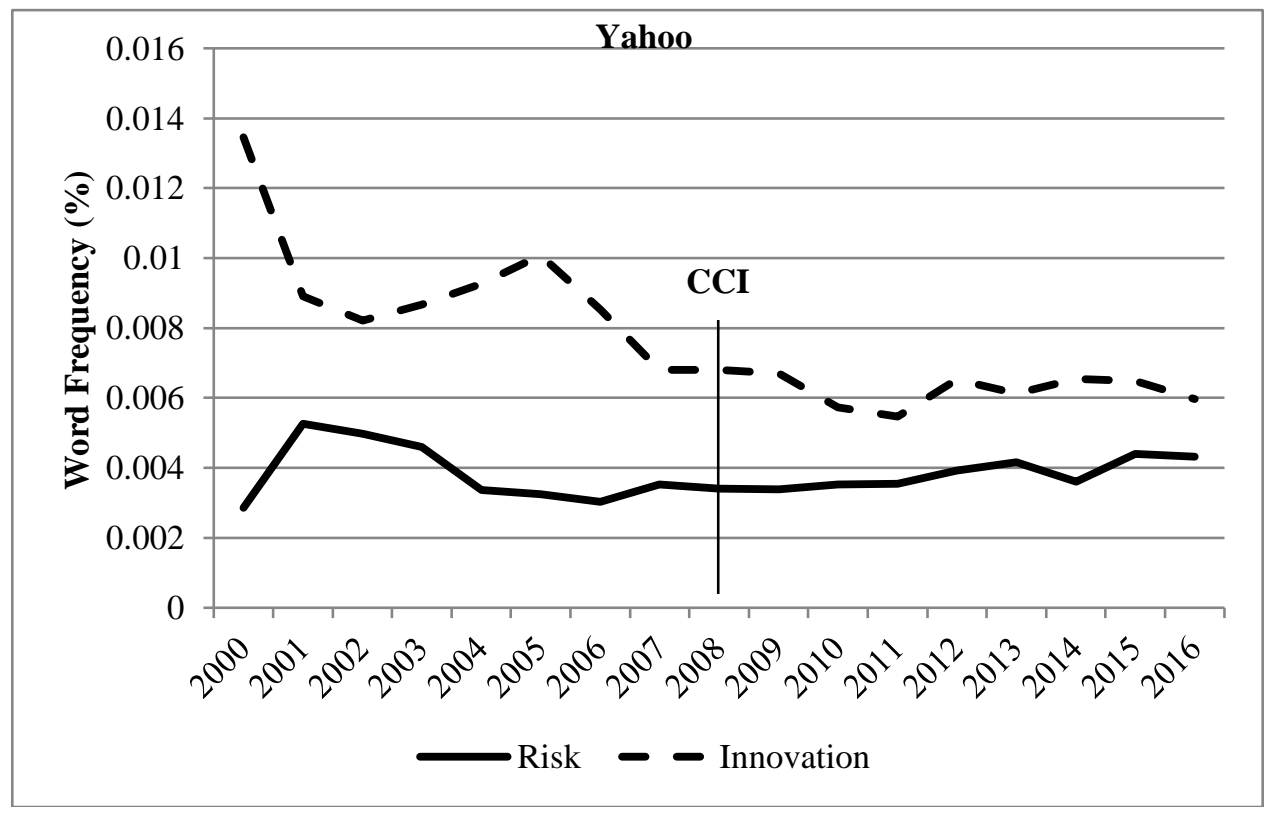

\section{A potential diagnostic in problematic corporate turnarounds}

A widely accepted view is that corporate crisis events are managed effectively by adopting a systematic approach that includes pre-planning, rehearsing scenario situations and reacting quickly to priority issues with full disclosure of information. It is a short-term view, and one that overlooks the potential for a crisis event to influence the health and performance of an organization over time. Arguably, when organizations are suffering from chronic underperformance the turnaround team should take into account any history of a crisis event that occurred years before. A plausible explanation for chronic corporate underperformance, could be that a severe environmental situation has created an inherited adaptive cultural response that has influenced the development and health of the organization over multiple generations. It is a diagnosis that could validate the need to make both a cultural and economic assessment of the company's situation.

Certainly the adaptive cultural responses for AIG and Yahoo in terms of their attitude and behaviors toward innovation and risk following a CCI were different. For AIG the gap between innovation and risk word frequencies was small at the time of the crisis, but has subsequently grown due to increased levels of risk attitude. The adaptive cultural response for Yahoo is interesting, since the gap between innovation and risk since the CCI has closed substantially, to the point where the adaptive cultural response to innovation and risk are almost the same. In essence, Yahoo viewed innovation as too risky and its corporate financial performance since the CCI has been disastrous. 
Published as: Oliver, J.J. (2020). Corporate turnaround failure: is the proper diagnosis transgenerational response? Strategy \& Leadership, Vol.48, Issue 3, pp.37-43

\section{The long-term consequences of trauma}

Corporate Crisis Incidents have the ability to create adaptive responses in organizational culture and performance, so much so, that their effects and consequences may reach far beyond their immediate impact. By looking at corporate turnaround cases through the lens of epigenetic theory and the notion of an inherited Transgenerational Response, we can better explain why organizations with chronic underperformance cannot be easily turned around. Furthermore, we can identify a specific moment in time when a crisis event created an adaptive change in corporate culture. Importantly, it seems this adaptation is inherited by future leaders of the firm. With this knowledge in hand, it will be easier to examine, unravel and manage the inherited cultural attitudes and behaviors that have combined to determine a traumatized firm's chronic underperformance.

\section{An overview of the methodology}

1. A Critical Corporate Incident (CCI) refers to a corporate crisis. These events are "critical" if they are clearly identifiable and result in subsequent corporate effects and consequences which influence the health and development of the firm. Of numerous corporate crisis events between 2000-2016, 17 cases were identified that had the potential to create effects and consequences that could result in chronic financial performance. From the 17 cases, four firms (AIG, Barclays Plc, Blackberry, Yahoo) were studied in-depth and seemingly evidenced a Transgenerational Response. The adaptive cultural responses of two firms, AIG and Yahoo, was examined by analyzing the word frequencies of "innovation" and "risk" words in their respective Corporate Annual Reports. The percentage of each innovation and risk words was then calculated against the total number of words in each annual report in order to demonstrate the relationship between innovation and risk, and ultimately, to identify any adaptive cultural response resulting from a CCI.

\section{A Corporate Generation}

A "corporate generation" has not been generally established as a standard period in business and management literature, however, this research posits that a corporate generation starts with the appointment of a new CEO and ends when that executive is replaced. It is a period in the life of a firm that is distinctive as each new CEO makes major corporate decisions, shapes long-term strategy and ultimately is responsible for delivering on corporate objectives and performance targets. A study by Tonello (2015) reported that the average tenure of an S\&P 500 CEO was 9.9 years. By implication, a firm appointing multiple CEOs in a relatively short space of time could be a key indicator for identifying Transgenerational Response effects.

\section{Chronic Corporate Underperformance}

Chronic corporate underperformance has been extensively researched in business and management literature, primarily with regards to "corporate turnaround and financial distress" using a number of financial indicators. This study used comparative share price performance, Market Capitalization, Operating Income, and Earnings Before Interest and Tax (EBIT) for their ability to provide longitudinal comparisons of corporate performance. The data was analyzed in terms of "what happened before the crisis event" and "what happen after the crisis event." The average percent increase or decrease in each financial variable in the years before and after the CCI was then calculated to illustrate corporate financial performance. For example, if the incident occurred in 2006, the Market Capitalization of the firm in 2006 was compared with the Average Market Capitalization figure prior to and 
Published as: Oliver, J.J. (2020). Corporate turnaround failure: is the proper diagnosis transgenerational response? Strategy \& Leadership, Vol.48, Issue 3, pp.37-43

following the CCI. The percent change in pre- and post-event averages were then compared to assess corporate performance effects of the incident. The use of averages has the advantage of smoothing the data in order to eliminate short-term volatility in the financial numbers, which in turn provides a clearer picture of the trend in corporate performance.

\title{
Notes
}

1. Kaati, G., Bygren, L. O., Pembrey, M., and Sjo“stro“m, M. (2007). "Transgenerational response to nutrition, early life circumstances and longevity," European Journal of Human Genetics, 15(7), 784. 2. Davidson, A. C., and Mellor, D. J. (2001). "The adjustment of children of Australian Vietnam veterans: is there evidence for the transgenerational transmission of the effects of war-related trauma?" Australian and New Zealand Journal of Psychiatry, 35(3), 345-351.

3. Yehuda, R., Engel, S. M., Brand, S. R., Seckl, J., Marcus, S. M., and Berkowitz, G. S. (2005), "Transgenerational effects of posttraumatic stress disorder in babies of mothers exposed to the World Trade Center attacks during pregnancy." The Journal of Clinical Endocrinology \& Metabolism, 90(7), 4115-4118.

4. Oliver, J.J. (2019), "Culture also eats innovation for breakfast!" Strategic Direction, Vol.35, No. 12, 1-3. 5. Tonello, M. (2015), "New Statistics and Cases of CEO Succession in the S\&P 500," The Harvard Law School Forum on Corporate Governance and Financial Regulation (https://corpgov.law. harvard.edu).

5. Tonello, M. (2015), "New Statistics and Cases of CEO Succession in the S\&P 500," The Harvard Law School Forum on Corporate Governance and Financial Regulation (https://corpgov.law. harvard.edu).

6. Martin J. Sullivan, President and CEO. AIG Annual Report (2006, p. 2).

7. Yahoo Annual Report (2015, p. 2).

\section{Acknowledgements}

This work was supported by the British Academy under grant SRG18R1\180437.

\section{Corresponding author}

John J Oliver can be contacted at: joliver@bournemouth.ac.uk

\begin{abstract}
About the author
John J Oliver is an Associate Professor at Bournemouth University, UK (joliver@bournemouth.ac.uk) and a Visiting Fellow at the University of Oxford. His previous Strategy \& Leadership article was "Is 'transgenerational response' a hidden cause of failed corporate turnarounds and chronic underperformance?” in Vol. 45, No.3, 2017.
\end{abstract}

